\title{
Consequences of Mutations and Abnormal Expression of SMAD4 in Tumors and T Cells
}

This article was published in the following Dove Press journal: OncoTargets and Therapy

\author{
Rongxue $\mathrm{Wan}^{1-3}$ \\ Jianguo Feng $\mathbb{D}^{2,4}$ \\ Liling Tang (D)
}

'Key Laboratory of Biorheological Science and Technology, Ministry of Education, College of Bioengineering, Chongqing University, Chongqing, 400044, People's Republic of China; ${ }^{2}$ National Key Discipline of Human Anatomy, School of Basic Medical Sciences, Southern Medical University, Guangzhou, Guangdong Province, People's Republic of China; ${ }^{3}$ Department of Human Anatomy, School of Basic Medical Sciences, Guangdong Medical University, Zhanjiang, Guangdong Province, People's Republic of China; ${ }^{4}$ Department of Anesthesiology, The Affiliated Hospital of Southwest Medical University, Luzhou, Sichuan Province, People's Republic of China
Correspondence: Jianguo Feng 1023-1063 Shatai South Road, Baiyun District, Southern Medical University, Guangzhou, 510515, People's Republic of China

Tel +86-1820-835-7473

Email ffengjianguo@।63.com

Liling Tang

83 Shabei Street, Shapingba District, Chongqing University, Chongqing, 400044, People's Republic of China Tel +86-1399-605-1730

Email tangliling@cqu.edu.cn

\begin{abstract}
SMAD4 is a typical tumor suppressor in the TGF- $\beta$ signaling pathway. In human cancers, SMAD4 is frequently mutated and inactivated. In recent years, the consequences of mutations and inactivation of SMAD4 are gradually becoming clearer. Most of the mutations have negative consequences and reduce the chances of survival of their carriers. Loss of SMAD4 functions due to mutations or abnormal expression can suppress the inhibition of tumor growth and support the tumor progression. Functions of SMAD4 and its variants in $\mathrm{T}$ cells are being studied extensively, to better understand the SMAD4 functions in T cells. In this review, we mainly discuss the recently reported consequences of mutations and abnormal expression of SMAD4 in tumors, and the effects of loss, deficiency or mutation of SMAD4 and its $\mathrm{T}$ cells, to show the use of SMAD4 mutations in cancer diagnosis and therapeutic strategies.
\end{abstract}

Keywords: SMAD4, mutation, abnormal expression, T cell, TGF- $\beta$

\section{Background}

The nomenclature of "Smad" was first termed in 1996, a contraction of the names of prototypic members Sma and Mad. ${ }^{1}$ These are intracellular transcription factors that regulate the TGF- $\beta$ signal transduction. The eight members of the Smad family of regulatory proteins are classified into three groups, according to their functions: receptor-activated Smads (R-Smads), co-mediator Smad (Co-Smad) and inhibitedSmads (I-Smads). Upon activation of TGF- $\beta$ signaling pathway, TGF- $\beta$ type I/II receptors (T $\beta \mathrm{R}-\mathrm{I} / \mathrm{T} \beta \mathrm{R}-\mathrm{II})$ complex phosphorylates SMAD2 and SMAD3, which are R-Smads, ${ }^{2}$ while the other R-Smads, viz., SMAD1/5/8, participate in the BMP/ Smads pathway, after being phosphorylated by the BMP type I/II receptors (BMPR I/BMPR II) complex. ${ }^{3}$ SMAD4, the co-Smad, also named as deleted in pancreatic cancer 4 (DPC4), is a tumor suppressor in many types of tumor cells. ${ }^{3,4}$ SMAD4 can complex with all the activated R-Smads, and transfer signals into the nucleus, to regulate the transcription of the target genes, controlling cell differentiation, proliferation and apoptosis. ${ }^{5}$ The I-Smads, including SMAD6 and SMAD7, inhibit the phosphorylation of SMAD4, competing to complex with R-Smads or disturbing the binding of Smad complex binding to DNA, resulting in negatively regulating TGF- $\beta /$ Smads signaling pathways. ${ }^{6-8}$

In the canonical TGF- $\beta /$ Smad signaling pathway, Smads regulate the communication between the nucleus and the cell microenvironment by shuttling between the cytosol and nucleus. ${ }^{9}$ Briefly, the signal is triggered by the binding of TGF- $\beta$ and T $\beta$ RII, activating the T $\beta$ RII, which further activates the T $\beta$ RI. This phosphorylates 
R-Smads, forming the phosphorylated-R-Smads/SMAD4 complexes, which are then transported into the nucleus, and interact with other transcription factors to regulate the expression of target genes. Transduction of this kind of signaling can be inhibited by I-Smads, to regulate the extent of activation of TGF- $\beta /$ Smad signaling.

The mechanisms of initiation and development vary among different tumors. Abnormal expression and accumulation of mutations in tumor-related genes are the major contributors to oncogenesis. ${ }^{10,11}$ SMAD4 is frequently mutated during cancerization of cells. ${ }^{12-16}$ Using high throughput sequencing technology, increasing number of SMAD4 mutations are being reported in the cancer cells and immune cells. These mutations can be new targets for cancer therapy. In this review, we discuss the structure and functions of SMAD4 and the consequences of abnormal expression and mutations of SMAD4 in tumor cells and T cells. This knowledge may provide new insights into the diagnoses and therapeutic strategies for SMAD4-associated tumors.

\section{Mutations That Affect the Functions of SMAD4 Protein Structure of SMAD4}

Human SMAD4 gene is located on the chromosome location $18 \mathrm{q} 21.1$, and is composed of 11 exons, spanning the fulllength (1659 bp) transcript of SMAD4. ${ }^{17}$ SMAD4 protein is composed of three domains: Mad Homology1 (MH1) domain at the N-terminus, Mad Homology2 (MH2) domain at the C-terminus, and a linker region between the MH1 and MH2 domains. ${ }^{17,18}$ As shown in Figure 1, the conserved MH1 domain is encoded by most parts of the exon 1 and 2, and contains sub-regions such as a nuclear localization signal (NLS) in the exon 1, essential for the role of SMAD4 in transcription, a DNA binding motif in the junction of exon 1 and exon 2, necessary for the binding of SMAD4 to the Smad-binding elements (SBE) in the promoters of the target genes, and a functional, leucine-rich nuclear export signal (NES) in the junction of exon 2 and 3, important for the role of SMAD4 in TGF- $\beta$ /Smads signaling pathway. ${ }^{19-22}$

The MH2 domain of SMAD4, necessary for forming the $\mathrm{R}-\mathrm{Smad} /$ co-Smad complex, is encoded by most of the exon 8 and exon 11 and entire of the exon9 to exon10 (Figure 1). ${ }^{23}$ The MH2 domain of R-Smads, but not of SMAD4, can be phosphorylated by the T $\beta R-I / T \beta R-I I$ complex. In addition, the $\mathrm{MH} 1$ and $\mathrm{MH} 2$ domains are antagonistic; as in the R-Smads, the MH2 domain of SMAD4 is negatively regulated by the $\mathrm{MH} 1$ and this regulation could be removed when MH2 domain was phosphorylated. ${ }^{24,25}$ The L3 loop, a motif in $\mathrm{MH} 2$ domain, could be recognized by Ski that has been identified affecting cell growth and muscle differentiation, ${ }^{26,27}$ disturbing the formation of SMAD4/ R-Smads complex, and negatively regulate the TGF- $\beta$, BMP and activin signaling pathways. ${ }^{28}$

Between the $\mathrm{MH} 1$ and $\mathrm{MH} 2$ domains is the prolinerich linker region. In the full-length SMAD4, the linker region is encoded by a part of exon 2 and exon 8 , and the entire of exon 3 to exon 7 (Figure 1). The linker region carries a nuclear export signal, crucial for the subcellular localization of SMAD4. ${ }^{29,30}$ A proline-rich Smad-activation domain (SAD), which is necessary for the role of SMAD4 in transcription, is also in the linker region. ${ }^{31}$ Crystal structure analysis showed that because of the proline-rich sequence, the SAD elements can activate SMAD4 for transcription by interacting with other transcription factors. ${ }^{32}$ Even though the mutated SMAD4 without SAD can complex with R-Smads or other transcription factors, these complexes are not sufficient to activate transcription. ${ }^{33}$ Because the lengths of

MH1

LINKER

MH2

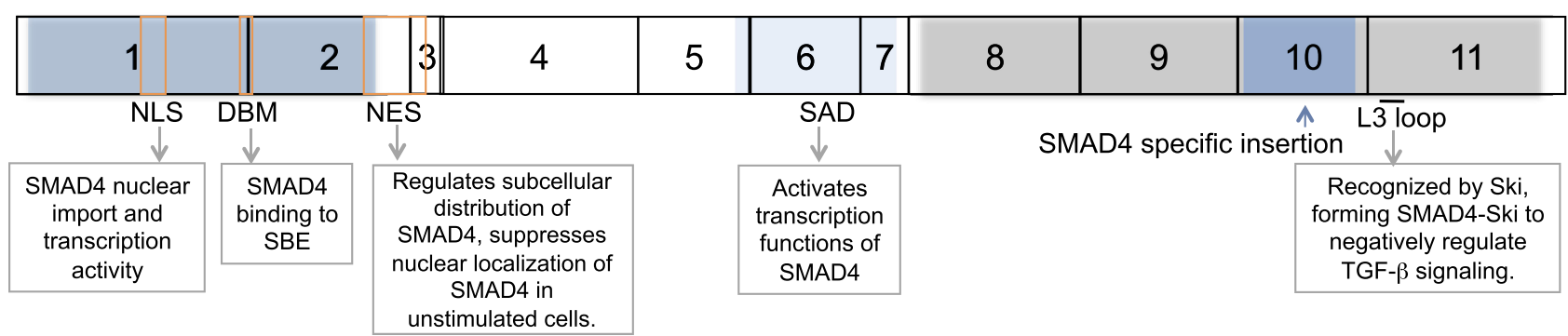

Figure I The schematic diagram to show the structure of SMAD4. SMAD4 is composed of three different domains, MHI, linker region and MH2 domain. Nuclear localization signal (NLS), DNA binding motif (DBM) and nuclear export signal (NES) are in MHI domain. And linker region has a Smad-activation domain (SAD). In MH2 domain, there is a region that is called SMAD4 specific insertion and MH2 mutation often occur in this region. L3 loop of MH2 domain is important for forming complex with R-Smads. 
the spliced variants or isoforms vary, the linker region is not conserved, unlike the $\mathrm{MH} 1$ or $\mathrm{MH} 2$ domains. Frequency of mutations in the linker region is high, and include silencing, missense, insertion-deletion, and frame-shift mutations. ${ }^{18}$

\section{Mutations of SMAD4 Occurring in Tumors}

Proliferation of cancer cells is inhibited by the TGF- $\beta$ signaling, which requires the participation of a functional SMAD4. ${ }^{34,35}$ However, SMAD4, a tumor suppressor gene, is frequently mutated or silenced during tumor initiation and development. About $50 \%$ of the pancreatic cancers have mutated SMAD4, and $15 \%$ of colorectal cancers carry SMAD4 mutations in the homozygous or hemizygous state. ${ }^{36,37}$ Mutations in SMAD4 inactivate the TGF- $\beta$ signaling in gastric tumors. ${ }^{38}$ Loss of SMAD4 leads to formation and promotion of metastases in the head and neck cancer, and the pancreatic cancer. ${ }^{39}$ In mice, SMAD4 and PTEN synergistically inhibit the forestomach squamous cell carcinoma, and mutations in them enhance the cell growth and carcinogenesis. ${ }^{40,41}$ In addition, the $\mathrm{MH} 2$ domain is more frequently mutated than the MH1 domain or the linker region. It is reported that the $\mathrm{MH} 2$ domain is a mutation hotspot region in SMAD4. ${ }^{42}$ In Juvenile Polyposis, 40-60\% patients were diagnosed with germline mutation of SMAD4, and about $85 \%$ of these mutations are seen in the $\mathrm{MH} 2$ domain, and just $15 \%$ of them occur in the MH1 and linker domains. ${ }^{43,44}$

In colorectal cancers, primary cancer lesions harbor a variety of mutations, including nonsense, frame-shift, missense, insertion, and deletion, while the most frequent ones are the missense mutations, ${ }^{45}$ which always have severe consequences. The somatic mutation of SMAD4 analysis showed that as high as $78.8 \%$ missense mutations were in $\mathrm{MH} 2$ domain, and mainly within the R-Smad binding region. ${ }^{45}$ Three other reported missense mutations in the $\mathrm{MH} 2$ domain may affect the binding of C-terminal region of SMAD4 with SMAD2 and SMAD3. A large number of missense mutations in the MH1 and MH2 domains of SMAD4 alter the stability of the protein, and particularly the $\mathrm{K} 45 \mathrm{~N}$ mutation in the MH1 domain disrupts the SMAD4 localized to the nucleus. ${ }^{45,46}$ Some mutations, such as missense mutation of L172M and T197I in the linker region, do not affect the functions of SMAD4 protein. ${ }^{45}$

\section{Mutations Negatively Regulate the Functions of SMAD4}

SMAD4 is involved in the TGF- $\beta$ /Smad signaling pathway, mainly in inhibiting cellular growth. Mutations in SMAD4 result in decreased activation of TGF- $\beta / \mathrm{Smad}$ signaling pathway. SMAD4 shuttles between the cytoplasm and the nucleus, using the NLS and NES present in the $\mathrm{MH} 1$ and $\mathrm{MH} 2$ domains. $^{22}$ Mutations in the NLS disrupt this nucleocytoplasmic shuttling, reducing the accumulation of SMAD4 in the nucleus, eventually inactivating the transcriptional function of SMAD4. ${ }^{22}$ In acute myelogenous leukemia, a heterozygous missense mutation in the $\mathrm{MH} 1$ domain prevented its DNAbinding, and a frame shift mutation in the $\mathrm{MH} 2$ domain inhibited the nuclear translocation (Table 1). ${ }^{47}$ Mutated SMAD4 with homozygous deletion of a 38 amino acid at the $\mathrm{MH} 2$ domain, failed to form the complexes with SMAD2 or SMAD3, and could not be recruited to DNA binding sites by other transcriptional factors. ${ }^{48}$

In some cases, mutations in the individual amino acids can have serious consequences. An overall 38\% point mutations in the SMAD4, detected among the patients with juvenile polyposis syndrome, occur mainly in the exon 8 and $9 .{ }^{49}$ In the MH2 domain, I500, which is conserved in many species, is close to the K519, a site of protein ubiquitination. A report showed that a single codon mutation in 1500 can cause Myhre syndrome. ${ }^{50}$ K507 in the L3 loop is a target site for ubiquitination, and participates in the recognition of phosphorylated R-Smads. ${ }^{51}$ When K507 is mutated, the complexes of SMAD4/R-Smads become non-functional and the transcriptional activity of SMAD4 decreases. ${ }^{51}$ Another set of two point mutations in the MH2 domain of SMAD4 from colorectal cancer cell lines also result in SMAD4 failing to form complexes with activated SMAD2, and a weaker response of SMAD4 to the TGF- $\beta$ stimulation (Table 1). ${ }^{36}$ R361C mutation in the C-terminus was detected in the patients of juvenile polyposis and HHT, negatively regulating the SMAD4 protein function by preventing its oligomerization. ${ }^{52,53}$ Similar spectra of somatic mutations were found in the pancreatic cancers and colorectal cancers. ${ }^{53-55}$ Carriers of SMAD4 mutations appear to have a higher risk of carcinogenesis. In colorectal cancers, a higher frequency of mutations in SMAD4 represents relatively advanced stages of cancer, probably distant metastasis. ${ }^{54}$ 
Table I Representative Mutations of SMAD4 in Different Cancers and the Impacts on the Functions of SMAD4

\begin{tabular}{|c|c|c|c|c|}
\hline Disease & $\begin{array}{l}\text { Mutated } \\
\text { Domain }\end{array}$ & Mutation Type & Results & References \\
\hline \multirow[t]{3}{*}{ Colorectal Cancer } & $\mathrm{MH} 2$ & $\begin{array}{l}\text { Deletion, Insertion, } \\
\text { Transition }\end{array}$ & Involve in distant metastasis & [54] \\
\hline & $\mathrm{MH} 2$ & $\begin{array}{c}\text { Missense }\left(\mathrm{D}^{351} \rightarrow \mathrm{H}, \mathrm{D}^{537}\right. \\
\rightarrow \mathrm{Y})\end{array}$ & Disrupt the interaction with SMAD2 & [36] \\
\hline & MHI & Transition (L43 to RI35) & Reduce the ability to bind DNA & [96] \\
\hline \multirow[t]{2}{*}{ Myhre Syndrome } & $\mathrm{MH} 2$ & Missense (p.R496C) & $\begin{array}{l}\text { Impair the ubiquitination of SMAD4; Affect the stability of } \\
\text { SMAD4/p-R-Smads complexes }\end{array}$ & [97] \\
\hline & $\mathrm{MH} 2$ & Missense (1500) & $\begin{array}{l}\text { Increase the stabilization of SMAD4; Perturb the binding } \\
\text { specificity or affinity of SMAD4 }\end{array}$ & {$[98,99]$} \\
\hline Breast Cancer & $\mathrm{MH} 2$ & $\begin{array}{l}\text { c. } 1350 \mathrm{G}>\mathrm{A}(\mathrm{p} . \mathrm{Q} 450 \mathrm{Q}) \\
\text { c. } 1214 \mathrm{~T}>\mathrm{C}(\mathrm{p} . \mathrm{F} 362 \mathrm{~F})\end{array}$ & Disrupt the exonic splicing enhancers (ESE) & {$[100]$} \\
\hline \multirow{2}{*}{$\begin{array}{l}\text { Acute } \\
\text { Myelogeneous } \\
\text { Leukemia }\end{array}$} & $\mathrm{MHI}$ & Missense (PI02L) & Inhibit DNA-binding ability & [47] \\
\hline & $\mathrm{MH} 2$ & $\begin{array}{l}\text { One frame shift }(D(483 \pm \\
552))\end{array}$ & Block nuclear translocation & [47] \\
\hline Cervical Cancer & $\mathrm{MH} 2$ & Transition G/A & - & {$[101]$} \\
\hline Liver Cancer & $\mathrm{MHI}$ & RI00T & No disruption on SMAD4 functions & [102] \\
\hline
\end{tabular}

Note: "_" means no reports showing the consequence of the mutations.

Chung and Mortelé ${ }^{56}$ reported a case, in which the patients with combined juvenile polyposis syndrome and hereditary hemorrhagic telangiectasia (JPS/HHT) diagnosed through MRI and endoscopic correlation, and recommended screening the patients using combined JPS/HHT for mutations in SMAD4 gene mutations. Due to mutation or deletion, SMAD4 was inactivated and posed a risk to the patients. In the pancreatic cancer, inactivation of SMAD4 reduces the chances of survival of the patients, and result in their poorer prognosis. ${ }^{57}$ Mutated SMAD4 is rapidly degraded through $\mathrm{SCF}^{\beta-\operatorname{TrCP} 1}$ E3 ligase-mediated protein ubiquitination. ${ }^{58}$ Wild type SMAD4 can also be ubiquitinated, leading to its inactivation. Recently, $\alpha \mathrm{B}$-crystallin, a small heat-shock protein, was found to be important for nuclear localization of SMAD4, and it was able to interact with E3-ubiquitin ligase to prevent the ubiquitination of SMAD4. ${ }^{59}$ However, not all mutations are harmful to SMAD4. The single codon mutation of $\mathrm{I} 500$ has two distinct consequences: causing Myhre syndrome and stabilizing SMAD4 (Table 1). ${ }^{50}$ These findings suggest that the mutations of SMAD4 are important in diagnosing cancer and devising effective therapies.

\section{Abnormal Expression of SMAD4 Benefits to Tumors}

SMAD4, the only co-Smad, is important in signal transduction through the classical TGF- $\beta /$ Smad pathway, and interacts with other transcription factors, including R-Smads, FAST-1, and TIF1- $\beta$, to regulate the proliferation, growth, and differentiation of cells. ${ }^{31,60-62}$ DeltaFosB was shown to positively regulate the mRNA level of SMAD4 in the goat mammary epithelial cells. ${ }^{63}$ In the rod photoreceptors of mature retina, neural retina leucine $(\mathrm{Nrl})$ is reported to control the expression of SMAD4. ${ }^{64}$ Methylation of the promoter of SMAD4 affects its expression as well.

Loss of SMAD4 expression was reported in many invasive cancers, such as ampulla of pancreatic cancer, colorectal cancer, vater carcinomas, breast carcinoma, resulting in failure to inhibit cancer cell growth. ${ }^{54,65-67}$ In different stages, expression patterns of different genes vary in the tumors. In pancreatic cancer, the expression of SMAD4/DPC4 was suppressed by miR483-3p and downregulation of SMAD4 expression was reported to have a role in the carcinogenesis of adrenocortical carcinoma. ${ }^{68}$ Expression of SMAD4 was also reported to 
be lost in gastrointestinal cancer due to the genomic deletion at chromosome $18 \mathrm{q}$, resulting in the cytologic grade and cellularity higher, also with destructive invasion, and lower overall survival. ${ }^{69}$ Park et $\mathrm{al}^{70}$ recently reported that the loss of expressions of SMAD4, p53, and E-cadherin, together promote the development and metastasis of gastric adenocarcinoma. It is reported that loss of SMAD4 enhances aggressive tumor behavior through up-regelating PGK1 in pancreatic ductal adenocarcinoma (PDAC) and $\mathrm{Yu}$ et al showed that the loss of SMAD4 expression predicts a poor overall survival in PDAC. ${ }^{71,72}$ It is becoming clear that switching of tumor-suppressive activity of TGF$\mathrm{b}$ to tumor-promoting interactions is the result of loss of SMAD4, and triggered by the Smad4-independent TGF- $\beta$ signaling. ${ }^{73}$ Loss of SMAD4 promotes the BMP-induced epithelial-mesenchymal transition (EMT) through the ROCK pathway in colorectal cancer. ${ }^{74}$ Loss of SMAD4 decreases the expression of Brca/Fanc, resulting in the accumulation of DNA damage leading to tumor formation. $^{73,75}$

Although SMAD4 expression is lost in many tumors, the SMAD2/3 expression remain unaltered, ${ }^{76}$ suggesting that there may be some molecules that, at least partially, compensate for the loss of SMAD4, allowing the TGF- $\beta$ / Smad signaling pathway to continue. Ahmed et al demonstrated that, when the human SMAD4 is mutated in breast cancer cells, resulting in its loss of function, the SMAD4 of Schistosoma mansoni could replace it, and respond to the TGF- $\beta$ signaling pathway. ${ }^{77}$ Mutations in the MH2 domain reduce the affinity of binding between SMAD4 and DNA, and weaken the transcriptional responses, and this is compensated by SMAD3. ${ }^{78,79}$ However, the mechanism of such a compensation for inactive SMAD4 due to mutations or abnormal expression remains unclear.

\section{Functions of SMAD4 and Its Mutants in T Cells SMAD4 Regulates T Cell Differentiation, Proliferation and Growth in TGF- $\beta$ - Dependent or -Independent Manner}

TGF- $\beta$ plays crucial roles in modulating the immune response and inflammation. Effector Th1 cells were associated with autoimmune diseases. IL-10, a cytokine produced by Th1, which was resulting from TGF-b mediated SMAD4 binding to the promoter of IL-10, was reported restrained autoimmune inflammation. ${ }^{80}$ In the human $\mathrm{T}$ cell line HuT78, treatment with TGF- $\beta$ induces the expression of TTP, which is regulated by Smad proteins. ${ }^{81}$ Th17 cells derived from the naïve T cells, can be induced by IL-6 and IL-21. In the context of IL-21, SMAD4 could suppress the differentiation of Th17 cells, by directly binding to the Rorc promoter region along with SKI. ${ }^{82}$ In presence of TGF- $\beta$, this suppression is eliminated, because of the degradation of SKI. ${ }^{83}$ SMAD4 is also reported important for regulating the proliferation of activated $T$ cells in TGF- $\beta$-independent manner, which mediated by the transcription factor Myc. ${ }^{84}$ Although SMAD4 deficiency does not affect the survival of T cells significantly, the proliferation, growth, and the TGF- $\beta$ induced differentiation of SMAD4-deficient $T$ cells were reported to be impaired. ${ }^{85}$ The cytotoxic function of $\mathrm{CD} 8^{+}$ $\mathrm{T}$ cells is important for the immune response. Generation of memory-precursor of $\mathrm{CD}^{+} \mathrm{T}$ cells was controlled by SMAD4, and its deficiency weakens the response of memory $\mathrm{CD}^{+} \mathrm{T}$ cells, as their cytotoxic function is partially impaired ${ }^{86}$ During chronic viral infection, the $\mathrm{CD} 8^{+}$and $\mathrm{CD}^{+} \mathrm{T}$ cells are suppressed. The differentiation and accumulation of $\mathrm{CD}^{+} \mathrm{T}$ cells were required SMAD4 $4{ }^{87} \mathrm{Kim}$ et al explored the role of SMAD4 in T cells from the nonobese diabetic mice with an autoimmune disease, and found that SMAD4 plays a protective role in the development of autoimmune Sjogren's syndrome. ${ }^{85,88}$ These findings suggest that the development of autoimmune diabetes benefits from SMAD4 deletion in T cells.

\section{Loss or Deficiency of SMAD4 in T Cells Promoting the Incidence of Diseases}

Although TGF-b/SMAD4 signaling was important for $\mathrm{T}$ cell function, SMAD4 loss or deficient in T cells was reported associated with incidence and progress of diseases, especially autoimmune diseases. The increased levels and functions of type 9 T-helper (Th9) cells involved in inflammatory disease, accompanied with increased Th2-cell activity. ${ }^{89}$ Further study indicated that SMAD4 was involved in Th2 differentiated into Th9 through TGF-b/SMAD3/SMAD4 and interferonregulatory factor4 (IRF-4) signaling pathway and loss expression of SMAD4 lead to Th2-related cytokines, such as IL-4 and IL-13, and serum IgA over-production, which was associated with the pathogenesis of human IgA nephropathy. ${ }^{89,90}$

Sjögren's syndrome (SS), an autoimmune disease, which usually studied in nonobese diabetic mice for pathology, targets the exocrine glands including salivary 
glands and lacrimal glands where mainly $\mathrm{CD}^{+} \mathrm{T}$ cells infiltrated in affected individuals. ${ }^{91,92}$ It is reported that deletion of T-cell-specific SMAD4 increased the activation of effector T cells leading to up-regulation of IL-17 in nonobese diabetic (NOD) mice. ${ }^{88}$ Donghee Kim et al reported that loss of SMAD4 increased the number of activated/memory $\mathrm{CD}^{+}{ }^{+} \mathrm{T}$ cell and elevated proliferation potential of effector $\mathrm{T}$ cells, and dysregulated $\mathrm{T}$ cell activation, which promoted the progress of autoimmune diabetes and the incidence of the disease. ${ }^{85}$ These results indicated that SMAD4 in T cells plays critical role in immune response affecting the development of SS in NOD mice.

\section{Mutations of SMAD4 in T Cells Promote the Tumor Development Showing Potential Targets for T Cell-Related} Therapy

Although SMAD4 deletion or deficiency is well studied in regulating $\mathrm{T}$ cells differentiation, proliferation, and growth, it is reported to be mutated in T cells as well, which usually promote tumor development. ${ }^{88-90}$ Two mutations of SMAD4, SMAD4 (P102L) and SMAD4 $\triangle$ (483-552), have been reported in acute myelogeneous leukemia. ${ }^{47}$ SMAD4 (P102L) lost its ability to bind to the Smad binding element (SBE), while SMAD4 $\triangle$ (483-552) blocks the translocation of SMAD4 into the nucleus, leading to loss of the transcription function of SMAD4. Thus, both of these interrupt the TGF- $\beta$ signaling triggered growth-inhibition process in leukemogenesis. ${ }^{47}$ The loss of SMAD4-dependent signaling in T cells leads to spontaneous epithelial cancers throughout the gastrointestinal tract in mice. ${ }^{93} S M A D 4^{-/-} \mathrm{T}$ cells produce abundant Th2-type cytokines including IL-5, IL-6, and IL-13, which are the known mediators of stromal expansion of plasma cells. ${ }^{93}$

With the development of immunotherapy, SMAD4 or its mutants are considered as potential targets for $\mathrm{T}$ cell-related therapy. SMAD4 mutations and other infiltrating immune markers, including CD15, CD117, and CD206, are thought to predict the cancer recurrence and survival of patients with pancreatic ductal adenocarcinoma (PDAC) patients

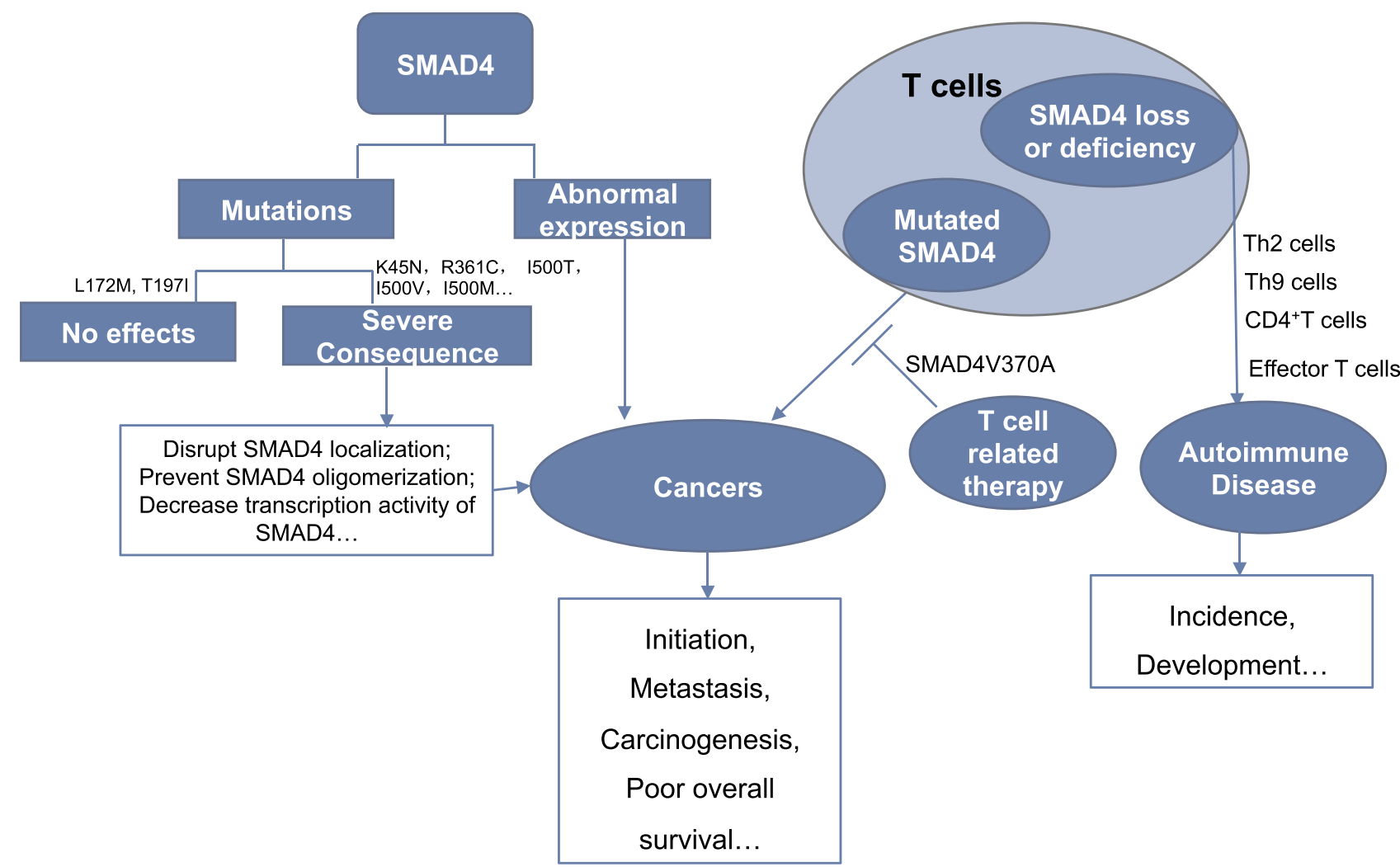

Figure 2 SMAD4 was reported mutated or abnormally expressed in tumors and T cells. These mutation and abnormal expression mainly resulted in severe consequence, which facilitates tumor initiation and growth, metastasis, carcinogenesis, and prognosis poor overall survival. T cells with mutated SMAD4 were reported promote tumor development. Recently, T cell-related therapy targeted on mutated Smad4 showed positive outcomes in tumor therapy. Loss or deficiency of SMAD4 in T cells was reported associated with the incidence and development of autoimmune diseases. 
after surgery. ${ }^{94}$ Mennonna et al ${ }^{95}$ reported SMAD4V370A mutation in the colorectal cancer samples, using highthroughput DNA sequencing. When they used peptides containing SMAD4V370A residue to stimulate T cells, the $\mathrm{CD} 8^{+} \mathrm{T}$ cells were induced, which could specifically recognize the CRC cells expressing SMAD4V370A. ${ }^{95}$ These new epitopes of SMAD4 can be new targets for T cellrelated cancer therapy.

T cell-specific SMAD4 was involved in T cell differentiation, proliferation and growth. The loss or deficiency of SMAD4 resulted in dysfunction of $\mathrm{T}$ cells and even the immune diseases; however, the mechanisms of SMAD4 loss or deficiency are still unclear and need more exploration. Interestingly, some mutations of SMAD4 could be targets for immunotherapy. Therefore, it is worthy to explore the functions or consequences of mutated SMAD4 to find more targets related to T cell-specific SMAD4.

\section{Conclusion}

SMAD4, a tumor suppressor gene is involved in the TGF- $\beta$ / Smads signal pathway to inhibit tumor cell growth and is frequently mutated in human tumors, leading to loss of function and put the patients at risk (Figure 2). Most of the mutations occur in the $\mathrm{MH} 1$ and $\mathrm{MH} 2$ domains, resulting in inactivation of SMAD4 and promoting the growth and distant metastasis of tumors. The consequences of mutations are complex and attractive, and the studies focused on this may provide new insights for new tumor therapeutic. The abnormal expression of SMAD4 also has negative consequences for patients, and new studies on the regulation of SMAD4 expression are needed. SMAD4 in T cells regulates cell survival, proliferation, differentiation, and growth. However, loss or deficiency of SMAD4 in T cells often leads to immune diseases and mutations of SMAD4 in $\mathrm{T}$ cells promote tumor development. Interestingly, some mutations could activate the immune system, showing their potential as targets for T cell-related therapies. ${ }^{94,95}$

Future studies need to explore the functions of mutated SMAD4, and new epitopes based on SMAD4 mutants in cancers and $\mathrm{T}$ cells. This work is expected to provide new insights into cancer diagnoses, anti-cancer drug design, and novel strategies for cancer therapeutics.

\section{Acknowledgment}

We would like to acknowledge the reviewers for their helpful comments on this paper.

\section{Funding}

This research was funded by the Natural Science Foundation of China (No.31670952, to Liling Tang), and the Natural Science Foundation of Guangdong Province (No. 2019A1515011854, to Rongxue Wan) and Postdoctoral Science Foundation of China (NO.2020M672561, to Rongxue Wan, NO.2019M662985, to Jianguo Feng.).

\section{Disclosure}

The authors declare that they have no competing interests.

\section{References}

1. Derynck R, Gelbart WM, Harland RM, et al. Nomenclature: vertebrate mediators of TGFbeta family signals. Cell. 1996;87 (2):173. doi:10.1016/S0092-8674(00)81335-5

2. Nakao A. TGF-beta receptor-mediated signalling through Smad2, Smad3 and Smad4. EMBO J. 1997;16(17):5353-5362. doi:10.10 93/emboj/16.17.5353

3. Liu F, Hata A, Baker JC, et al. A human Mad protein acting as a BMP-regulated transcriptional activator. Nature. 1996;381 (6583):620-623. doi:10.1038/381620a0

4. Kim SK. DPC4, a candidate tumor suppressor gene, is altered infrequently in head and neck squamous cell carcinoma. Cancer Res. 1996;56(11):2519-2521.

5. $\mathrm{Xu} \mathrm{X}$, Brodie SG, Yang X, et al. Haploid loss of the tumor suppressor Smad4/Dpc4 initiates gastric polyposis and cancer in mice. Oncogene. 2000;19(15):1868-1874. doi:10.1038/sj.onc.120 3504

6. Feng XH, Derynck R. Specificity and versatility in tgf-beta signaling through Smads. Annu Rev Cell Dev Biol. 2005;21: 659-693. doi:10.1146/annurev.cellbio.21.022404.142018

7. Shi WB. GADD34-PP1c recruited by Smad7 dephosphorylates TGF beta type 1 receptor. J Cell Biol. 2004;164(2):291-300. doi:10.1083/jcb.200307151

8. Hata A, Lagna G, Massague J, et al. Smad6 inhibits BMP/Smad1 signaling by specifically competing with the Smad4 tumor suppressor. Genes Dev. 1998;12(2):186-197. doi:10.1101/gad.12. 2.186

9. Moustakas A, Heldin $\mathrm{CH}$. From mono- to oligo-Smads: the heart of the matter in TGF-beta signal transduction. Genes Dev. 2002;16(15):1867-1871. doi:10.1101/gad.1016802

10. Weinberg RA. How cancer arises. Sci Am. 1996;275(3):62-70. doi:10.1038/scientificamerican0996-62

11. Fearon ER, Vogelstein B. A genetic model for colorectal tumorigenesis. Cell. 1990;61(5):759-767. doi:10.1016/00928674(90)90186-I

12. Rozenblum E. Tumor-suppressive pathways in pancreatic carcinoma. Cancer Res. 1997;57(9):1731-1734.

13. Oliner JD, Kinzler KW, Meltzer PS, et al. Amplification of a gene encoding a p53-associated protein in human sarcomas. Nature. 1992;358(6381):80-83. doi:10.1038/358080a0

14. Reifenberger G, Liu L, Ichimura K, et al. Amplification and overexpression of the MDM2 gene in a subset of human malignant gliomas without p53 mutations. Cancer Res. 1993;53 (12):2736-2739.

15. Shapiro GI, Edwards CD, Kobzik L, et al. Reciprocal Rb inactivation and p16INK4 expression in primary lung cancers and cell lines. Cancer Res. 1995;55(3):505-509.

16. Bartkova J. The p16-cyclin D/Cdk4-pRb pathway as a functional unit frequently altered in melanoma pathogenesis. Cancer Res. 1996;56(23):5475-5483. 
17. Hahn SA, Schutte M, Hoque ATMS, et al. DPC4, a candidate tumor suppressor gene at human chromosome 18q21.1. Science. 1996;271(5247):350-353. doi:10.1126/science.271.5247.350

18. Lazzereschi D, Nardi F, Turco A, et al. A complex pattern of mutations and abnormal splicing of Smad4 is present in thyroid tumours. Oncogene. 2005;24(34):5344-5354. doi:10.1038/sj. onc. 1208603

19. Watanabe M, Masuyama N, Fukuda M, et al. Regulation of intracellular dynamics of Smad4 by its leucine-rich nuclear export signal. EMBO Rep. 2000;1(2):176-182. doi:10.1093/emboreports/kvd029

20. Baburajendran N, Jauch R, Tan CYZ, et al. Structural basis for the cooperative DNA recognition by Smad4 MH1 dimers. Nucleic Acids Res. 2011;39(18):8213-8222. doi:10.1093/nar/gkr500

21. Zboralski D, Böckmann M, Zapatka M, et al. Divergent mechanisms underlie Smad4-mediated positive regulation of the three genes encoding the basement membrane component laminin-332 (laminin-5). BMC Cancer. 2008;8(p):215. doi:10.1186/1471-2407-8-215

22. Xiao Z, Latek R, Lodish HF. An extended bipartite nuclear localization signal in Smad4 is required for its nuclear import and transcriptional activity. Oncogene. 2003;22(7):1057-1069.

23. Feng XH. The tumor suppressor Smad4/DPC4 and transcriptional adaptor $\mathrm{CBP} / \mathrm{p} 300$ are coactivators for smad3 in TGF-betainduced transcriptional activation. Genes Dev. 1998;12 (14):2153-2163. doi:10.1101/gad.12.14.2153

24. Hata A, Lo RS, Wotton D, et al. Mutations increasing autoinhibition inactivate tumour suppressors Smad2 and Smad4. Nature. 1997;388(6637):82-87. doi:10.1038/40424

25. Qin BY, Chacko BM, Lam SS, et al. Structural basis of Smad1 activation by receptor kinase phosphorylation. Mol Cell. 2001;8 (6):1303-1312. doi:10.1016/S1097-2765(01)00417-8

26. Colmenares C, Stavnezer E. The ski oncogene induces muscle differentiation in quail embryo cells. Cell. 1989;59(2):293-303. doi:10.1016/0092-8674(89)90291-2

27. Berk M. Mice lacking the ski proto-oncogene have defects in neurulation, craniofacial, patterning, and skeletal muscle development. Genes Dev. 1997;11(16):2029-2039. doi:10.1101/ gad.11.16.2029

28. Wu JW, Krawitz AR, Chai J, et al. Structural mechanism of Smad4 recognition by the nuclear oncoprotein Ski: insights on Ski-mediated repression of TGF-beta signaling. Cell. 2002;111 (3):357-367. doi:10.1016/S0092-8674(02)01006-1

29. Pierreux CE, Nicolás FJ, Hill CS. Transforming growth factor beta-independent shuttling of Smad4 between the cytoplasm and nucleus. Mol Cell Biol. 2000;20(23):9041-9054. doi:10.1128/ MCB.20.23.9041-9054.2000

30. Fornerod M. CRM1 is an export receptor for leucine-rich nuclear export signals. Cell. 1997;90(6):1051-1060. doi:10.1016/S00928674(00)80371-2

31. de Caestecker MP, Hemmati P, Larisch-Bloch S, et al. Characterization of functional domains within Smad4/DPC4. J Biol Chem. 1997;272 (21):13690-13696. doi:10.1074/jbc.272.21.13690

32. Qin B, Lam SS, Lin K. Crystal structure of a transcriptionally active Smad4 fragment. Structure. 1999;7(12):1493-1503. doi:10.1016/S0969-2126(00)88340-9

33. de Caestecker MP. The Smad4 activation domain (SAD) is a proline-rich, p300-dependent transcriptional activation domain. J Biol Chem. 2000;275(3):2115-2122. doi:10.1074/jbc.275.3. 2115

34. Chen L. Pokemon inhibits transforming growth factor beta-smad4-related cell proliferation arrest in breast cancer through specificity protein 1. J Breast Cancer. 2019;22 (1):15-28. doi:10.4048/jbc.2019.22.e11

35. Zhao Y. Astragaloside IV inhibits cell proliferation in vulvar squamous cell carcinoma through the TGF-beta/Smad signaling pathway. Dermatol Ther. 2019;32(4):e12802.
36. De Bosscher K, Hill CS, Nicolás FJ. Molecular and functional consequences of Smad4 C-terminal missense mutations in colorectal tumour cells. Biochem J. 2004;379(Pt 1):209-216. doi:10.1042/bj20031886

37. Woodford-Richens KL. SMAD4 mutations in colorectal cancer probably occur before chromosomal instability, but after divergence of the microsatellite instability pathway. Proc Natl Acad Sci U S A. 2001;98(17):9719-9723. doi:10.1073/pnas.171321498

38. Powell SM. Inactivation of Smad4 in gastric carcinomas. Cancer Res. 1997;57(19):4221-4224.

39. Malkoski SP, Wang XJ. Two sides of the story? Smad4 loss in pancreatic cancer versus head-and-neck cancer. FEBS Lett. 2012;586(14):1984-1992. doi:10.1016/j.febslet.2012.01.054

40. Teng Y. Synergistic function of Smad4 and PTEN in suppressing forestomach squamous cell carcinoma in the mouse. Cancer Res. 2006;66(14):6972-6981. doi:10.1158/0008-5472.CAN-06-0507

41. Rocha BR, Colli SDR, Barcelos LM, et al. Age-dependent expression of Pten and Smad4 genes in the urogenital system of Wistar rats. Acta Cir Bras. 2014;29(Suppl 1):34-38. doi:10.1590/ S0102-86502014001300007

42. Iacobuzio-Donahue CA. Missense mutations of MADH4: characterization of the mutational hot spot and functional consequences in human tumors. Clin Cancer Res. 2004;10 (5):1597-1604. doi:10.1158/1078-0432.CCR-1121-3

43. Gallione C, Aylsworth AS, Beis J, et al. Overlapping spectra of SMAD4 mutations in juvenile polyposis (JP) and JP-HHT syndrome. Am J Med Genet A. 2010;152A(2):333-339. doi:10. 1002/ajmg.a.33206

44. Calva-Cerqueira D, Chinnathambi S, Pechman B, et al. The rate of germline mutations and large deletions of SMAD4 and BMPR1A in juvenile polyposis. Clin Genet. 2009;75(1):79-85. doi:10.1111/j.1399-0004.2008.01091.x

45. Fleming NI, Jorissen RN, Mouradov D, et al. SMAD2, SMAD3 and SMAD4 mutations in colorectal cancer. Cancer Res. 2013;73 (2):725-735. doi:10.1158/0008-5472.CAN-12-2706

46. De Roock W, Jonker DJ, Di Nicolantonio F, et al. Association of KRAS p.G13D mutation with outcome in patients with chemotherapy-refractory metastatic colorectal cancer treated with cetuximab. JAMA. 2010;304(16):1812-1820. doi:10.1001/ jama.2010.1535

47. Imai Y, Kurokawa M, Izutsu K, et al. Mutations of the Smad4 gene in acute myelogeneous leukemia and their functional implications in leukemogenesis. Oncogene. 2001;20(1):88-96. doi:10. 1038/sj.onc. 1204057

48. Maurice D. Loss of Smad4 function in pancreatic tumors: c-terminal truncation leads to decreased stability. J Biol Chem. 2001;276(46):43175-43181. doi:10.1074/jbc.M105895200

49. Aretz S. High proportion of large genomic deletions and a genotype phenotype update in 80 unrelated families with juvenile polyposis syndrome. $J$ Med Genet. 2007;44(11):702-709. doi:10.1136/jmg.2007.052506

50. Le Goff C. Mutations at a single codon in Mad homology 2 domain of SMAD4 cause Myhre syndrome. Nat Genet. 2012;44 (1):85-88. doi:10.1038/ng.1016

51. Morén A. Differential ubiquitination defines the functional status of the tumor suppressor Smad4. J Biol Chem. 2003;278 (35):33571-33582. doi:10.1074/jbc.M300159200

52. Gallione CJ. SMAD4 mutations found in unselected HHT patients. J Med Genet. 2006;43(10):793-797. doi:10.1136/ jmg.2006.041517

53. Woodford-Richens KL, Rowan AJ, Poulsom R, et al. Comprehensive analysis of SMAD4 mutations and protein expression in juvenile polyposis: evidence for a distinct genetic pathway and polyp morphology in SMAD4 mutation carriers. $\mathrm{Am}$ J Pathol. 2001;159(4):1293-1300. doi:10.1016/S0002-9440(10) 62516-3 
54. Miyaki M, Iijima T, Konishi M, et al. Higher frequency of Smad4 gene mutation in human colorectal cancer with distant metastasis. Oncogene. 1999;18(20):3098-3103. doi:10.1038/sj.onc.1202642

55. Hahn SA. Homozygous deletion map at $18 \mathrm{q} 21.1$ in pancreatic cancer. Cancer Res. 1996;56(3):490-494.

56. Chung AD, Mortelé KJ. Combined juvenile polyposis syndrome and hereditary hemorrhagic telangiectasia (JPS/HHT) with MRI and endoscopic correlation. Clin Imaging. 2019;54:37-39. doi:10.1016/j.clinimag.2018.11.011

57. Blackford A, Serrano OK, Wolfgang CL, et al. SMAD4 gene mutations are associated with poor prognosis in pancreatic cancer. Clin Cancer Res. 2009;15(14):4674-4679. doi:10.1158/ 1078-0432.CCR-09-0227

58. Yang L. Acute myelogenous leukemia-derived SMAD4 mutations target the protein to ubiquitin-proteasome degradation. Hum Mutat. 2006;27(9):897-905. doi:10.1002/humu.20387

59. Bellaye PS. The small heat-shock protein $\alpha \mathrm{B}$-crystallin is essential for the nuclear localization of Smad4: impact on pulmonary fibrosis. J Pathol. 2014;232(4):458-472. doi:10.1002/path.4314

60. Kageyama H. DPC4 splice variants in neuroblastoma. Cancer Lett. 1998;122(1-2):187-193. doi:10.1016/S0304-3835(97)003 89-3

61. Chen X, Weisberg E, Fridmacher V, et al. Smad4 and FAST-1 in the assembly of activin-responsive factor. Nature. 1997;389 (6646):85-89. doi:10.1038/38008

62. Hesling C. Antagonistic regulation of EMT by TIF $1 \gamma$ and Smad4 in mammary epithelial cells. EMBO Rep. 2011;12(7):665-672. doi:10.1038/embor.2011.78

63. Zheng $\mathrm{H} . \triangle \mathrm{FosB}$ regulates $\mathrm{Ca}^{+}$release and proliferation of goat mammary epithelial cells. Gene. 2014;545(2):241-246. doi:10.10 16/j.gene.2014.05.023

64. Yu J. Altered expression of genes of the Bmp/Smad and Wnt/calcium signaling pathways in the cone-only Nrl-/- mouse retina, revealed by gene profiling using custom cDNA microarrays. J Biol Chem. 2004;279(40):42211-42220. doi:10.1074/jbc.M408223200

65. Wilentz RE. Loss of expression of Dpc4 in pancreatic intraepithelial neoplasia: evidence that DPC4 inactivation occurs late in neoplastic progression. Cancer Res. 2000;60(7):2002-2006.

66. McCarthy DM, Hruban RH, Argani P, et al. Role of the DPC4 tumor suppressor gene in adenocarcinoma of the ampulla of Vater: analysis of 140 cases. Mod Pathol. 2003;16(3):272-278. doi:10.1097/01.MP.0000057246.03448.26

67. Chen H. Extracellular signal-regulated kinase signaling pathway regulates breast cancer cell migration by maintaining slug expression. Cancer Res. 2009;69(24):9228-9235. doi:10.1158/ 0008-5472.CAN-09-1950

68. Wang C, Sun Y, Wu H, et al. Distinguishing adrenal cortical carcinomas and adenomas: a study of clinicopathological features and biomarkers. Histopathology. 2014;64(4):567-576. doi:10.1111/ his. 12283

69. Davison JM, Hartman DA, Singhi AD, et al. Loss of SMAD4 protein expression is associated with high tumor grade and poor prognosis in disseminated appendiceal mucinous neoplasms. Am J Surg Pathol. 2014;38(5):583-592. doi:10.1097/PAS.0000000000000194

70. Park JW, Jang SH, Park DM, et al. Cooperativity of E-cadherin and Smad4 loss to promote diffuse-type gastric adenocarcinoma and metastasis. Mol Cancer Res. 2014;12(8):1088-1099. doi:10.1158/1541-7786.MCR-14-0192-T

71. Yu KH, Ricigliano M, McCarthy B, et al. Circulating tumor and invasive cell gene expression profile predicts treatment response and survival in pancreatic adenocarcinoma. Cancers (Basel). 2018;10(12):467. doi:10.3390/cancers10120467

72. Liang C, Shi S, Qin Y, et al. Localisation of PGK1 determines metabolic phenotype to balance metastasis and proliferation in patients with SMAD4-negative pancreatic cancer. Gut. 2020;69 (5):888-900. doi:10.1136/gutjnl-2018-317163
73. Wu F, Weigel KJ, Zhou $\mathrm{H}$, et al. Paradoxical roles of TGF- $\beta$ signaling in suppressing and promoting squamous cell carcinoma. Acta Biochim Biophys Sin (Shanghai). 2018;50(7):730. doi:10.1093/abbs/gmy013

74. Voorneveld PW, Kodach LL, Jacobs RJ, et al. Loss of SMAD4 alters BMP signaling to promote colorectal cancer cell metastasis via activation of Rho and ROCK. Gastroenterology. 2014;147 (1):196-208.e13. doi:10.1053/j.gastro.2014.03.052

75. Bornstein S. Smad4 loss in mice causes spontaneous head and neck cancer with increased genomic instability and inflammation. J Clin Invest. 2009;119(11):3408-3419. doi:10.1172/JCI38854

76. Antony ML. Changes in expression, and/or mutations in TGF-beta receptors (TGF-beta RI and TGF-beta RII) and Smad 4 in human ovarian tumors. J Cancer Res Clin Oncol. 2010;136 (3):351-361. doi:10.1007/s00432-009-0703-4

77. Osman A, Niles EG, LoVerde PT. Expression of functional Schistosoma mansoni Smad4: role in Erk-mediated transforming growth factor beta (TGF-beta) down-regulation. J Biol Chem. 2004;279(8):6474-6486. doi:10.1074/jbc.M310949200

78. Ten Dijke P, Miyazono K, Heldin CH. Signaling inputs converge on nuclear effectors in TGF-beta signaling. Trends Biochem Sci. 2000;25(2):64-70. doi:10.1016/S0968-0004(99)01519-4

79. Morén A, Itoh S, Moustakas A, et al. Functional consequences of tumorigenic missense mutations in the amino-terminal domain of Smad4. Oncogene. 2000;19(38):4396-4404. doi:10.1038/sj. onc. 1203798

80. Huss DJ. TGF-beta signaling via Smad4 drives IL-10 production in effector Th1 cells and reduces T-cell trafficking in EAE. Eur J Immunol. 2011;41(10):2987-2996. doi:10.1002/eji.201141666

81. Ogawa K. Transcriptional regulation of tristetraprolin by transforming growth factor-beta in human T cells. J Biol Chem. 2003;278(32):30373-30381. doi:10.1074/jbc.M304856200

82. Zhang S, Zhang G, Wan YY. SKI and SMAD4 are essential for IL-21-induced Th17 differentiation. Mol Immunol. 2019;114:260-268. doi:10.1016/j.molimm.2019.07.029

83. Zhang S. Reversing SKI-SMAD4-mediated suppression is essential for T. Nature. 2017;551(7678):105-109. doi:10.1038/ nature 24283

84. Gu A-D, Zhang S, Wang Y, et al. A critical role for transcription factor Smad4 in T cell function that is independent of transforming growth factor $\beta$ receptor signaling. Immunity. 2015;42 (1):68-79. doi:10.1016/j.immuni.2014.12.019

85. Kim D, Lee SM, Jun HS. Impact of T-cell-specific Smad4 deficiency on the development of autoimmune diabetes in NOD mice. Immunol Cell Biol. 2017;95(3):287-296. doi:10.1038/icb.2016.98

86. Cao J, Zhang X, Wang Q, et al. Smad4 represses the generation of memory-precursor effector $\mathrm{T}$ cells but is required for the differentiation of central memory T cells. Cell Death Dis. 2015;6(11): e1984. doi:10.1038/cddis.2015.337

87. Lewis GM, Wehrens EJ, Labarta-Bajo L, et al. TGF- $\beta$ receptor maintains CD4 T helper cell identity during chronic viral infections. J Clin Invest. 2016;126(10):3799-3813. doi:10.1172/ JCI87041

88. Kim D, Kim JY, Jun HS. Smad4 in T cells plays a protective role in the development of autoimmune Sjogren's syndrome in the nonobese diabetic mouse. Oncotarget. 2016;7(49):80298-80312. doi:10.18632/oncotarget.13437

89. Abdelaziz MH. Th2 cells as an intermediate for the differentiation of naive T cells into Th9 cells, associated with the Smad3/Smad4 and IRF4 pathway. Exp Ther Med. 2020;19(3):1947-1954. doi:10.3892/etm.2020.8420

90. Inoshita H, Kim B-G, Yamashita M, et al. Disruption of Smad4 expression in $\mathrm{T}$ cells leads to $\operatorname{IgA}$ nephropathy-like manifestations. PLoS One. 2013;8(11):e78736. doi:10.1371/journal.pone. 0078736 
91. Christodoulou MI, Kapsogeorgou EK, Moutsopoulos HM. Characteristics of the minor salivary gland infiltrates in Sjogren's syndrome. $J$ Autoimmun. 2010;34(4):400-407. doi:10.1016/j.jaut.2009.10.004

92. Versnel MA. Id3 knockout mice as a new model for sjogren's syndrome: only a T cell defect or more? Immunity. 2004;21 (4):457-458. doi:10.1016/j.immuni.2004.10.003

93. Kim BG, Li C, Qiao W, et al. Smad4 signalling in T cells is required for suppression of gastrointestinal cancer. Nature. 2006;441(7096):1015-1019. doi:10.1038/nature04846

94. Wang WQ, Liu L, Xu H-X, et al. Infiltrating immune cells and gene mutations in pancreatic ductal adenocarcinoma. Br J Surg. 2016;103(9):1189-1199. doi:10.1002/bjs.10187

95. Mennonna D, Maccalli C, Romano MC, et al. T cell neoepitope discovery in colorectal cancer by high throughput profiling of somatic mutations in expressed genes. Gut. 2017;66(3):454-463. doi:10.1136/gutjnl-2015-309453

96. Jones JB, Kern SE. Functional mapping of the MH1 DNA-binding domain of DPC4/SMAD4. Nucleic Acids Res. 2000;28(12):2363-2368. doi:10.1093/nar/28.12.2363

97. Caputo V, Bocchinfuso G, Castori M, et al. Novel SMAD4 mutation causing Myhre syndrome. Am J Med Genet A. 2014;164(7):1835-1840. doi:10.1002/ajmg.a.36544
98. Le Goff C, Mahaut C, Abhyankar A, et al. Mutations at a single codon in Mad homology 2 domain of SMAD4 cause Myhre syndrome. Nat Genet. 2012;44(1):85-U118.

99. Caputo V, Cianetti L, Niceta M, et al. A restricted spectrum of mutations in the SMAD4 tumor-suppressor gene underlies myhre syndrome. Am J Hum Genet. 2012;90(1):161-169. doi:10.1016/j. ajhg.2011.12.011

100. Tram E. Identification of germline alterations of the mad homology 2 domain of SMAD3 and SMAD4 from the Ontario site of the breast cancer family registry (CFR). Breast Cancer Res. 2011;13(4).

101. Maliekal TT, Antony M-L, Nair A, et al. Loss of expression, and mutations of Smad 2 and Smad 4 in human cervical cancer. Oncogene. 2003;22(31):4889-4897. doi:10.1038/sj.onc.1206806

102. Xu J, Attisano L. Mutations in the tumor suppressors Smad2 and Smad4 inactivate transforming growth factor beta signaling by targeting Smads to the ubiquitin-proteasome pathway. Proc Natl Acad Sci U S A. 2000;97(9):4820-4825. doi:10.1073/pnas.97. 9.4820

\section{Publish your work in this journal}

OncoTargets and Therapy is an international, peer-reviewed, open access journal focusing on the pathological basis of all cancers, potential targets for therapy and treatment protocols employed to improve the management of cancer patients. The journal also focuses on the impact of management programs and new therapeutic agents and protocols on patient perspectives such as quality of life, adherence and satisfaction. The manuscript management system is completely online and includes a very quick and fair peer-review system, which is all easy to use. Visit http://www.dovepress.com/ testimonials.php to read real quotes from published authors. 